\title{
O PLANEJAMENTO E A REVISÃO DE TEXTOS NA PRÁTICA PEDAGÓGICA DE PROFESSORES DO ENSINO FUNDAMENTAL
}

\author{
T.F. SILVA ${ }^{1}$ e S.R.K. GUIMARÃES ${ }^{2}$ \\ Pontifícia Universidade Católica do Paraná, Universidade Federal do Paraná \\ thalifolmann@gmail.com ${ }^{1}$ \\ Submetido 09/02/2017 - Aceito 14/02/2020 \\ DOI: $10.15628 /$ holos.2020.5634
}

\begin{abstract}
RESUMO
Objetivou-se analisar a prática pedagógica destinada à produção de textos a fim de identificar as estratégias didáticas adotadas para o planejamento e a revisão da produção dos estudantes. Foram realizadas trinta e uma horas de observação da prática de professoras de 4ำ e 5o anos do Ensino Fundamental. Verificou-se que nas atividades de planejamento as professoras propiciaram a leitura de diferentes textos e promoveram discussões sobre os conteúdos que seriam abordados nas produções. As atividades de revisão foram prevalentes após o término da primeira versão dos textos. Conclui-se
\end{abstract}

que os encaminhamentos observados não possibilitaram aos estudantes relevante melhoria no desempenho em relação à coesão e à coerência nos textos produzidos e, principalmente, na gestão consciente dos elementos constitutivos dos diferentes gêneros textuais. Infere-se que o planejamento e a revisão são atividades metatextuais que contribuem para o desempenho na escrita e, portanto, são ações que precisam ser contempladas na prática pedagógica para um eficiente processo de ensino-aprendizagem da produção textual.

PALAVRAS-CHAVE: Processo de produção textual, Revisão de textos, Habilidades metatextuais.

\section{PLANNING AND PREPARATION OF TEXTS IN THE PEDAGOGICAL PRACTICE OF PRIMARY SCHOOL TEACHERS}

\begin{abstract}
The objective was to analyze the pedagogical practice concerning student-produced texts and identify the didactic strategies adopted for planning and reviewing students' production. The practice of 4th and 5 th grade teachers was observed for 31 hours. We verified that during planning activities, the teachers allowed students to read different texts and encouraged discussions concerning the content that would be addressed in their writing. Review activities were prevalent after students finished their texts' first drafts.
\end{abstract}

\begin{abstract}
The conclusion is that the suggestions we observed did not help the students to significantly improve their performance concerning the texts' cohesion and coherence, and more importantly, did not aid in improving the conscious management of constructive elements of different textual genres. We infer that planning and review are metatextual activities that contribute to written performance and, therefore, are actions that should be addressed during teaching practice aiming an efficient teaching-learning process of text production.
\end{abstract}

KEYWORDS: Text production process; Text review; Metatextual skills. 


\section{INTRODUÇÃO}

A tarefa de corrigir os textos produzidos pelos alunos está atrelada à função do professor de diferentes níveis de escolaridade. Muitos profissionais acreditam que essa modalidade de correção possibilita o aperfeiçoamento da produção escrita e que, portanto, cabe ao docente corrigir a produção do aluno, destacando os elementos linguísticos inadequados. Em alguns casos, solicita-se a reescrita do texto para que o estudante altere o que foi indicado pelo professor. Em outros, apenas evidencia-se os erros que devem ser evitados num próximo trabalho.

Embora a correção de textos pelo professor seja importante para melhorar o desempenho dos estudantes, ela por si só não é suficiente para promover a competência na escrita. Considerase que o desempenho na composição de textos não depende somente das correções efetuadas pelo professor. A competência na escrita depende de estratégias didáticas que promovam a reflexão sobre a linguagem como, por exemplo, encaminhamentos pedagógicos que possam desenvolver a capacidade de: compreensão e manipulação dos morfemas (habilidade metamorfológica), controle intencional e emprego consciente da sintaxe da língua (habilidade metassintática); controle, de forma deliberada, da ordenação dos enunciados no texto (habilidade metatextual).

Para o aprimoramento da competência escrita, os estudantes precisam realizar tarefas que possibilitem o pensar sobre o modo como procedem antes ou durante a produção de um texto, a fim de desenvolver habilidades metacognitivas relacionadas ao processo de produção. Também, precisam reconhecer a escrita como atividade necessária no cotidiano e, por isso, uma atividade que tenha sentido quando realizada no contexto escolar. Além disso, conforme destacou Antunes (2016), os estudantes precisam compreender que planejar e revisar o texto são atividades essenciais no ato de escrever.

O planejamento e a revisão são atividades que permitem a reflexão sobre os diversos elementos constitutivos de um texto, seja na etapa de projeto, durante sua elaboração ou ao término da primeira versão. Essas atividades podem propiciar o desenvolvimento das habilidades metatextuais dos estudantes que, segundo Gombert (1992), envolve o monitoramento da estrutura, da coerência e da coesão dos textos.

Diversos autores salientam a importância do planejamento como uma das etapas que constituem o processo de produção de textos (Calkins, 2002; Hayes \& Flower, 1980; Jolibert \& cols., 1994; Lucena, 2013; Spinillo, 2015), tendo em vista seu papel na organização do que será registrado. Para Leal e Brandão (2007), bons resultados na escrita estão diretamente relacionados à capacidade de planejar o modo como os componentes linguísticos serão estruturados para alcançar a compreensão do leitor.

Normalmente, planejamento não é uma atividade desempenhada por escritores iniciantes, embora seja uma prática comum aos escritores mais experientes, capazes de fazê-lo, inclusive, 
mentalmente (Travaglia, 2016). Entretanto, planejar quais e como os conteúdos irão compor o texto constitui-se um exercício necessário ao escritor iniciante que ao registrar o seu plano estará delimitando o que será contemplado na produção, ou seja, o planejamento servirá como ponto de partida para a construção do texto.

Além do escritor planejar o texto a ser construído, em atividades na sala de aula é possível que um grupo de escritores ou até mesmo o professor registre previamente as ideias a serem contempladas na produção. Conforme recomenda Travaglia (2016), o ideal é que ocorra uma variação nessas condições, que o planejamento seja elaborado ora pelos alunos, ora pelo professor.

Ao planejar o texto, primeiramente, define-se tema, objetivos, destinatário, contexto, suporte, gênero e a linguagem a ser empregada (Antunes, 2016). Após a delimitação desses aspectos é fundamental planejar a organização tópica do gênero adotado, ou seja, definir como as informações serão agrupadas. Todo texto tem um tópico discursivo, ou seja, um tema que precisa ser organizado de acordo com os segmentos tópicos, conforme as partes que o compõe. 0 agrupamento das informações pode ocorrer em um único parágrafo ou em mais de um (Travaglia, 2016).

Entretanto, esta organização tópica requer que o escritor tenha tido contato com textos do mesmo gênero a ser elaborado (Pereira, 2008). A leitura e exploração de textos com a mesma estrutura composicional possibilitam a recuperação e aquisição de conhecimentos sobre o gênero. Esses saberes poderão ser incorporados quando o texto tomar seu formato. Como afirmam Leal e Melo (2007, p.21), "para aprender a escrever, é necessário ler (e ler muito!)". Ler textos com a mesma estrutura composicional possibilita verificar as características do gênero, identificar os elementos linguísticos empregados para dar coerência e coesão à obra. Possibilita, também, que o planejamento seja elaborado com maior qualidade, considerando as especificidades dos textos que funcionam como "fonte" para o que se pretende escrever (Pereira, 2008).

Além da leitura de texto-fonte, no processo de ensino-aprendizagem de produção textual considera-se apropriada a leitura de textos de variados gêneros, o que possibilita a comparação entre eles, ou seja, a identificação de semelhanças e diferenças nas composições escritas. Em outras palavras, no processo de ensino-aprendizagem é fundamental a leitura de variados gêneros textuais, pois a comparação entre a estrutura prototípica de diferentes composições contribui para o desenvolvimento das habilidades metatextuais.

Além de encaminhar a leitura de diferentes gêneros, a prática pedagógica voltada para o desenvolvimento da capacidade de produção textual deve focalizar a análise crítica do planejamento de modo que seja possível ao escritor prever inadequações, tendo em vista a necessidade de acréscimos e/ou substituição de conteúdos no texto a ser construído. Discussões entre estudantes e professores, bem como, a leitura do plano por um colega ou pelo grupo, podem ser estratégias de revisão a serem adotadas ainda nessa etapa, conforme a indicação de Calkins (2002). 
Nesta perspectiva, o planejamento é suscetível à reorganização a partir das necessidades percebidas pelo próprio escritor ou, em atividades de sala de aula, a partir das necessidades sentidas pelos colegas e/ou professor. Essas sucessivas revisões poderão provocar mudanças no que o escritor havia planejado, já na etapa anterior ao desenvolvimento escrito do texto.

A partir destas considerações, é possível verificar a importância da revisão, atividade que permeia todas as fases do processo de produção. Para Antunes (2016), tanto planejar o que será registrado, quanto revisar o texto são tarefas que favorecem a competência escrita dos estudantes. Por essa razão, ambas precisam ser contempladas na prática pedagógica.

Na opinião de Rocha (1999, p.60), a revisão é uma atividade essencial ao desempenho discente em relação à escrita "[...] na medida em que viabiliza o exercício de revisitar o texto, explicitar questões, verificar o não explicado, repensar a escrita de palavras, reconstruir, retificar". Conforme afirma Brandão (2007, p. 120), a revisão possibilita “[...] pensar sobre o que foi ou está sendo escrito e encontrar meios para melhor dizer o que se quer dizer, reelaborando e reescrevendo o já escrito".

Diversos autores definiram a revisão como a etapa final do processo de produção de textos (Calkins, 2002; Hayes \& Flower, 1980; Jolibert \& cols., 1994; Lucena, 2013; Pereira, 2008; Spinillo, 2015). No entanto, concordam com a possibilidade de revisar a escrita na etapa de planejamento, como discutido anteriormente, durante a elaboração do texto ou após a produção de uma primeira versão. Embora seja possível revisar o texto em diferentes momentos de sua composição, verifica-se o predomínio dessa tarefa após a elaboração da primeira versão, tanto na prática pedagógica, quanto em pesquisas científicas.

Para Calkins (2002), a revisão efetuada durante a elaboração de texto é chamada de conferência, na medida em que os trechos são lidos e analisados, torna-se possível verificar inadequações. Essa leitura analítica pode ocorrer quando o próprio autor lê os trechos escritos, analisando-os, antes de prosseguir para uma nova parte da produção, ou, ainda, quando solicita a outra pessoa que realize a leitura, para emitir opinião quanto às ideias registradas, bem como, sobre a continuidade do texto. Nas atividades de sala de aula, a pessoa que atuará como interlocutor pode ser outro estudante ou até mesmo o professor. Para tanto, é importante explicitar ao grupo que não é somente o professor quem poderá conferir os textos, mas que os alunos podem contribuir nessa tarefa, uma vez que "[...] quando compartilham seus esboços entre si, durante ou depois da escrita, seus diálogos frequentemente impulsionam o texto para frente" (Calkins, 2002, p.92).

No processo de ensino-aprendizagem a revisão pode ocorrer, também, durante a elaboração de um texto coletivo em que o professor atua como escriba e registra o texto construído em parceria com os alunos. Nestas situações o professor pode

[...] discutir com os alunos sobre conteúdos a serem inseridos no texto, auxiliando-os na geração, seleção e organização desses conteúdos; analisar as melhores alternativas para expressar linguisticamente, de modo coerente e coeso, os conteúdos a serem tratados no 
texto; registrar, discutindo, se conveniente, questões relativas à ortografia, pontuação, concordância gramatical, entre outras; discutir sobre a adequação das escolhas antes mencionadas à finalidade e ao interlocutor (Melo \& Silva, 2007, p. 90).

Além de abordar esses aspectos na revisão coletiva, o professor pode orientar a revisão em atividades realizadas pelos próprios alunos, organizando-os em duplas. Assim, enquanto um aluno atua como escriba, o outro desempenha a função de revisor, buscando ajustar o texto em construção por meio de discussões com o seu parceiro.

Há casos de revisões efetuadas durante a elaboração do texto em que o(s) escritor(es) realizam alterações que são percebidas pelas marcas que deixam no papel. Essas marcas expressam que leitura e escrita se integram na constituição do texto, uma vez que além de escrever, há necessidade de ler as ideias registradas (Abaurre, Fiad \&Mayrink-Sabinson, 1997).

Além de enfatizar a importância da revisão em todas as etapas da produção textual é fundamental destacar também o papel mediador do professor no processo de ensinoaprendizagem da escrita. Esta mediação deve ser ajustada às necessidades dos alunos, os quais precisam ser estimulados a refletir sobre os diferentes elementos do texto, para o aprimoramento da composição escrita, para tanto não é adequada a simples indicação do que deve ser alterado ou acrescentado ao texto. É igualmente necessário que os estudantes sejam capazes de focalizar a atenção no conteúdo e na linguagem, minimizando a preocupação com questões ortográficas. Neste sentido, Calkins (2002) sugere que não é recomendada, por exemplo, a construção de banco de palavras, listas de palavras e/ou o uso de dicionários, durante o processo de escrita propriamente dito. Esses recursos poderão ser empregados quando a primeira versão estiver construída.

Como já foi mencionado, a revisão após o término da primeira versão do texto predomina nas pesquisas brasileiras sobre essa temática. Estas pesquisas apresentam diversas estratégias didáticas que podem ser adotadas a fim de possibilitar a reflexão acerca dos elementos linguísticos contemplados em um texto.

Alguns estudos relatam a escrita de bilhetes aos alunos como estratégia para a revisão de textos (D'elia, 2007; Nascimento, 2009). Ao utilizar esta estratégia, o professor escreve bilhetes aos seus alunos indicando explicitamente o que precisam alterar ou questionando-os para que pensem sobre as ideias apresentadas no texto. D'elia (2007) e Nascimento (2009) concordam que este é um recurso que pode promover a reflexão sobre a linguagem, mas destacam a importância de considerar alguns aspectos ao se adotar este tipo de procedimento. O primeiro deles é que o aluno pode simplesmente responder as questões, sem uma reflexão consciente sobre o texto. Outra dificuldade verificada em alunos que estão em fase inicial da leitura, pode ser a falta de compreensão da mensagem registrada no bilhete (D'elia, 2007). Ainda, há um terceiro problema, o tempo para que o professor possa analisar o texto e elaborar as orientações e/ou questionamentos que serão indicados aos alunos (Nascimento, 2009). 
Outra estratégia didática utilizada para auxiliar os estudantes no processo de revisão de suas produções é a marcação dos textos com diferentes símbolos (códigos) indicativos do que eles devem rever e reelaborar. Assim, o estudo de Costa (2010) mostrou diferentes símbolos para representar as orientações que os alunos precisavam seguir: "observar o que foi dito, procurar escrever de maneira mais clara", "usar expressões para fazer ligações de um período a outro", "evitar muitas informações no mesmo parágrafo", "evitar informações novas como se já tivessem sido apresentadas", entre outras.

Além do estabelecimento de códigos para nortear a revisão textual, estudos brasileiros comprovaram que a revisão em parceria intensifica a reflexão sobre o texto (Spinillo, 2015; Dutra, 2011; Andrade, 2010). Na pesquisa realizada por Spinillo (2015), com estudantes de 7 a 9 anos, foi possível verificar maior incidência de substituições no texto quando as revisões foram efetuadas em parceria com um colega, do que nas efetuadas individualmente em que a maior parte dos participantes apenas acrescentou informações à produção escrita. A autora concluiu que "um ambiente colaborativo em que o aluno, juntamente com o colega, é estimulado a revisar textos problemáticos, pode contribuir para o uso de diferentes estratégias de revisão e facilitar a descoberta de que o texto pode ser objeto de múltiplas reformulações" (Spinillo, 2015, p. 238).

Brandão (2007) sugere que esse ambiente colaborativo também pode ser promovido por meio da revisão coletiva em que o professor seleciona um dos textos elaborados pelos alunos para que seja revisado pelo grupo. Nestas situações, primeiramente, o professor analisa os conhecimentos linguísticos empregados adequadamente e os enfatiza. Posteriormente, prossegue destacando e promovendo a reflexão dos alunos a respeito dos aspectos a serem aprimorados. Desse modo, “[...] o diálogo entre 'escritores' funciona como estratégia pedagógica para a descoberta profunda do funcionamento dos textos" (Pereira, 2008, p. 32).

Dentro desta perspectiva, Dalla-Bona (2012) enfatiza que a ausência ou a pouca interação entre os pares, além da impossibilidade de escrever mais de uma versão do texto, se mostram como fatores que interferem negativamente no desenvolvimento da capacidade de escrita. A pesquisadora elencou a revisão de texto entre pares e a análise textual coletiva como estratégias didáticas a serem incorporadas na prática pedagógica.

Em relação aos aspectos a serem priorizados na revisão, Brandão (2007) recomenda que, primeiramente, ocorra reflexão sobre a coerência, uma vez que é um dos elementos linguísticos fundamentais do texto. Por sua vez, Pereira (2008) alerta para o fato de que a tarefa de revisar um texto não seja considerada simplesmente uma correção. É uma tarefa que deve objetivar o aprimoramento da escrita, permitindo que sejam feitas supressões, permutas, substituições e/ou acréscimos. Estas quatro ações são denominadas de pontos cardeais da operação de reescrita e, por essa razão, devem ser contempladas na revisão.

Em síntese, a revisão é uma atividade metatextual na medida em que envolve o monitoramento da composição textual - sua estrutura, coerência e coesão - favorecendo o aperfeiçoamento da escrita. Ela pode ser realizada após a elaboração da primeira versão, mas 
também, pode ser proposta nas demais etapas do processo de produção, na textualização ou planejamento.

É neste contexto teórico que este estudo se insere, com o objetivo de verificar como o planejamento e a revisão de textos são contemplados na prática pedagógica, uma vez que parece haver, na realidade educacional brasileira, uma preocupação maior com a quantidade de produções e não com o tempo desprendido para a reflexão sobre a língua. Também, uma excessiva preocupação com correções ortográficas e gramaticais, demonstrando a crença de que o menor número de erros dessa natureza possa garantir a competência na escrita, conforme a constatação de Antunes (2016).

Assim, neste artigo relatam-se os resultados de uma pesquisa de observação da prática pedagógica em duas turmas de Ciclo II da Rede Municipal de Curitiba, em que se buscou identificar as estratégias didáticas adotadas para o planejamento e revisão de textos, bem como analisar como tais tarefas influenciam no desempenho dos estudantes na produção de textos.

A finalidade deste estudo foi tentar fornecer elementos para responder duas questões principais: Que estratégias didáticas são adotadas para promover o planejamento e a revisão de textos em sala de aula? As estratégias adotadas pelas professoras participantes do estudo possibilitam melhora no desempenho dos estudantes em produção de textos?

\section{MÉTODO}

\section{1 Participantes}

A pesquisa foi desenvolvida numa escola da Rede Municipal de Curitiba, que atende estudantes do Ensino Fundamental, tanto na modalidade regular, quanto na Educação de Jovens e Adultos. A escolha da instituição ocorreu em função da solicitação da diretora da escola, bem como da professora do 5o ano, que expressaram interesse de participar do estudo. A inclusão de uma segunda turma (4ํano) na observação deveu-se a um novo pedido da diretora da unidade.

Sendo assim, participaram da pesquisa três professoras, vinte e sete alunos de 4음 ano e vinte e dois alunos de 50 ano. Todos os participantes terão a identidade mantida em sigilo. Quando houver necessidade, os estudantes serão identificados pela letra " $A$ " e uma numeração e as professoras pelas siglas: P1, P2 e P3.

\section{2 Material e procedimentos}

Este estudo foi realizado por meio de "observação investigativa" (Sampieri, Collado \& Lucio, 2013) e focalizou tanto a prática das professoras como a atuação dos alunos em sala de aula. Os episódios foram registrados no Protocolo de Observação, que contempla: a identificação da turma, horário e tempo de observação, a atividade proposta e o encaminhamento pedagógico das docentes, a atuação dos discentes, além de outras informações relevantes que emergiram durante a observação. 
Além disso, foram coletados dados de produção dos estudantes (que depois de analisados foram devolvidos): atividades efetuadas no livro didático, registros feitos nos cadernos e produções realizadas em folhas avulsas distribuídas pelas professoras.

A observação correu durante trinta e uma horas, ao longo de quinze dias de imersão no contexto escolar. Nesse período, foi possível acompanhar o trabalho pedagógico destinado à produção de textos informativos, narrativos e argumentativos.

O estudo foi submetido previamente ao Comitê de Ética da Universidade Federal do Paraná - Setor de Ciências da Saúde, obtendo parecer de acordo para a sua realização (número CAAE 56027916.8.0000.0102).

\section{RESULTADOS E DISCUSSÃO}

Inicialmente é importante salientar que esse trabalho teve como objetivo investigar as estratégias didáticas adotadas pelas professoras participantes do estudo para promover o planejamento e a revisão de textos em sala de aula, buscando verificar se as estratégias adotadas possibilitam melhoria no desempenho dos estudantes em produção de textos. Assim, a apresentação e análise dos dados levantados serão realizadas em duas subseções. Na primeira, será feita a apresentação e a análise dos dados referentes às etapas de planejamento contempladas na prática pedagógica das professoras, bem como o efeito dessas práticas nas produções dos alunos. Em seguida, serão apresentadas atividades pedagógicas que foram implementadas pelas professoras com o objetivo de ensinar como proceder revisão textual, discutindo como essas atividades de ensino refletiram nas produções textuais dos alunos.

Destaca-se que essa investigação teve um alcance descritivo e, tendo em vista o seu enfoque qualitativo, os dados observados serão analisados e discutidos, a partir da descrição de alguns episódios que foram destacados devido ao seu potencial para responder as questões propostas no início do estudo.

\subsection{O ensino do planejamento de textos na prática pedagógica}

O primeiro episódio que será analisado é o planejamento do texto que teve como tema: "Pão, o alimento da nossa terra para nossa gente". A elaboração desse texto objetivava a participação dos alunos do 4ำ ano em um concurso promovido por uma empresa privada do ramo alimentício. Antes da produção, a professora (P1) escreveu a frase/tema no quadro e pediu que os alunos fizessem a leitura. Como estavam em duas professoras (P1 e P3) na sala, elas realizaram uma discussão sobre o assunto com os estudantes e, posteriormente, solicitaram que as crianças começassem a produção. Nesse momento, uma delas (P1) acrescentou "Qualquer dúvida, chama a gente". Ao término da produção, um dos alunos demonstrou não ter compreendido o destino 
do texto, o que possibilitou constatar que a finalidade da produção não foi suficientemente esclarecida.

É pertinente destacar que, antes de iniciarem a escrita do texto, os alunos foram orientados quanto ao uso de letra inicial maiúscula e, também, orientados a definirem o título logo no início da produção. Entretanto, ao invés de privilegiar somente orientações quanto às questões normativas, as professoras poderiam ter explicado a finalidade e os objetivos do texto que os alunos deveriam escrever, explicitando detalhadamente a estrutura do gênero, visto que estas instruções poderiam contribuir com a ativação de conhecimentos linguísticos composicionais demandados durante a produção e a revisão de textos.

Na etapa de planejamento é imprescindível, segundo Travaglia (2016, p. 88), definir "o que dizer, para quem dizer, para que dizer (com que objetivos)". Após a delimitação desses elementos, se decide sobre a estrutura composicional e sobre o gênero textual a ser elaborado que envolve a organização tópica do texto. Também Koch e Elias (2016, p. 160) destacam que ao planejar um texto deve-se ter em mente questões relacionadas ao tema ou assunto que considere o objetivo para a escrita, a situação comunicativa que envolve o escritor e o leitor, o que o leitor sabe e, portanto, o escritor não precisa explicitar, o que o leitor não sabe e o escritor precisa explicitar e, por último, o gênero textual que deve ser produzido.

Na situação observada as professoras promoveram uma discussão sobre a temática do texto a ser produzido, envolvendo principalmente os seguintes conteúdos: a origem do pão, como ele é produzido atualmente, como era feito e em quais refeições o pão é utilizado. Entretanto, pouco do que é preconizado por Travaglia (2016), assim como, por Koch e Elias (2016) foi abordado.

Outra estratégia que poderia ter sido adotada pelas professoras seria apresentar e analisar com os alunos os textos produzidos pelos participantes do concurso cultural em anos anteriores, ou mesmo outras composições escritas que apresentassem a mesma estrutura textual, demandada naquele momento. Neste sentido, Pereira (2008) salienta que a leitura de textos do mesmo gênero contribui para que os estudantes compreendam o funcionamento da escrita, bem como, as questões normativas a serem atendidas na produção.

Em estudo realizado com alunos do 4을 ano, Dalla-Bona (2012) comprovou que a leitura de textos literários contribuiu para a competência dos estudantes na escrita desse gênero de texto. Por essa razão, salientou que para compreender como funciona a linguagem escrita faz-se necessário o contato com vários textos do mesmo gênero.

A explicitação e exploração do gênero poderiam, por exemplo, evitar a preocupação excessiva dos alunos com a extensão do texto, fato observado num episódio em que um aluno pergunta à professora (P1): "Profe, terminei?" Em seguida seu colega responde: "Mas tá pouco para uma produção de texto!".

Destaca-se que a professora ( $P 1$ ) delimitou o que deveria conter em cada um dos trechos da produção individual, a partir da participação oral dos alunos. Ao observar a produção de um 
dos alunos, foi possível verificar que ele seguiu a orientação dada por ela quanto à organização dos temas, porém, apenas utilizou-se dos itens elencados previamente.

A origem do pão
O pão foi criado na Pércia 12 mil anos a trás. Ele era feito na pedra quente e saia duro e seco.
Ele é feito com trigo que é colhido, triturado. Ele vai fabica colocão, farinha água e fermento vai para o
forno e pronto.
Ele é servido no café da manhã e café da tarde, o pão é feito de trigo para a gente comer.
Texto produzido pelo aluno A9.

Quadro 1: Produção individual sobre o pão.

Na produção de outra criança também foi possível verificar que a organização tópica se deu por meio de respostas aos itens apresentados pela professora. O que diferencia a primeira produção apresentada desta segunda é o fato da aluna consultar um texto informativo discutido no dia anterior e que estava colado no caderno. A estratégia adotada pela aluna possibilitou que ela agregasse maior quantidade de informações ao texto dela, o que foi positivo. Entretanto, faltou ensino explícito de como articular as informações no texto, de forma a torná-lo mais coeso.

\begin{tabular}{l} 
Como o pão era a 18 mil anos atrás \\
O pão é uma invenção Pérsa, eles os pães não eram igual ao de hoje. Eram duros e nutritivos eles eram \\
feitos sobre uma pedra quente. \\
Hoje em dia ele é feito com esses ingredientes: Fermento, água, gordura, sal açúcar e leite. Antigamente \\
ele era duro hoje ele é macio e mais saboroso. Os egípcios criaram o processo de fermentação para o pão ficar \\
melhor para se comer. \\
O pão é utilizado no café com queijo, presunto, requeijão, doce de leite, pasta de amendoim, creme de \\
avelã, margarina e manteiga pa janta com carne e feijão. \\
Tem varios tipos de pães Pão de queijo, integral, forma, baguete, pão de leite, pão de aipi, pão de milho, \\
pão francês, Pão de forma e pão do aroz. \\
Todos no mundo inteiro comem pão seja de manhã de tarde e de noite. \\
Quadro 2: Produção Inaıvidual sobre o pao. Texto produzido pela aluna A10. \\
\hline
\end{tabular}

Nesses episódios, a organização tópica dos textos parece ter influenciado a produção, como também, a compreensão dos estudantes. Essa constatação possibilita considerar que se houvesse uma melhor elaboração do "esqueleto conceitual" (Antunes, 2016) haveria maior possibilidade dos estudantes elaborarem uma composição escrita com maior coerência e com maior utilização de elementos coesivos. Como salienta Travaglia (2016), a organização dos conteúdos é fundamental para o desenvolvimento de competências relacionadas tanto à escrita quanto à leitura. Portanto, é uma tarefa que pode ser solicitada em situações didáticas que tenham como objetivo a produção e/ou a compreensão de textos.

Assim sendo, concorda-se com Pereira (2008, p.12) quando defende que a escola deve propiciar uma "relação de identidade do sujeito com a língua e não uma relação alienada", o que ocorre quando ao realizarem tarefas de escrita os alunos apresentam "uma simples justaposição de enunciados de diferentes origens, apenas com a finalidade de mostrar que sabem 'coisas'". A autora salienta que a escrita é uma forma de construir o pensamento e não pode ser encarada 
apenas como uma tarefa escolar, tendo em vista que se constitui de "um trabalho (meta) cognitivo, (meta) linguístico e (meta) discursivo".

Percebe-se, então, a importância de planejar o texto a ser construído, registrar previamente o que poderá ser abordado, bem como, de promover reflexões sobre a língua, ainda nessa etapa inicial do processo de produção. Além disso, a elaboração do planejamento é especialmente fundamental para escritores iniciantes que, posteriormente com a prática, poderão planejar sem necessitar de um registro por escrito (Travaglia, 2016).

Em outro episódio, verificou-se que a professora (P1) recomendou aos alunos que se preocupassem com a qualidade do texto. No entanto, se mostrou incoerente ao delimitar a quantidade de linhas para a produção de um final diferente para o conto João e Maria. Neste dia, a professora (P1) estava conduzindo a atividade sem o auxílio da outra regente e ao dar início à produção recomendou que os alunos escrevessem 10 linhas. Em suas palavras: "Não vai terminar a história em duas linhas! Vão pensar em algo que deixe o texto bem legal, interessante!" Além disso, sugeriu que organizassem o final em dois parágrafos.

A elaboração de um final diferente para a história ocorreu após a exploração de um texto narrativo contemplado na sequência didática do livro. Inicialmente, a professora (P1) leu o texto e discutiu algumas expressões, embora não tenha privilegiado a discussão sobre palavras consideradas desconhecidas pelos estudantes. Aproveitou a discussão para explorar expressões comumente usadas como marcadores no início e término de contos de fadas, um dos elementos característicos do gênero em questão. Acredita-se que durante esta atividade a professora poderia ter ampliado a discussão realizada envolvendo outros elementos constituintes do gênero conto de fadas, tais como: tempos verbais, caracterização dos personagens e espaços, entre outros.

Destaca-se que ao trabalhar a sequência proposta no livro a professora realizou as atividades relacionadas à compreensão do texto, bem como às que versavam sobre questões gramaticais e ortográficas. Todavia, as atividades destinadas especificamente à produção textual não foram contempladas. Essas possibilitariam comparar a versão modificada com o conto original; ler outras histórias a fim de comparar a introdução e a conclusão apresentadas nas narrativas; escrever diferentes inícios e analisar o modo como estes textos narrativos costumam terminar.

Em uma das observações realizadas na turma de 50 ano, houve a exploração de diferentes textos narrativos, antes da produção ser efetuada pelos estudantes. Para iniciar, a professora (P2) instigou os alunos a pensar sobre o título do primeiro texto que seria lido "Contos de Mistério". Durante a leitura, discutiu algumas expressões presentes no texto, analisou com os alunos as inferências que precisavam ser realizadas para entender a narrativa, bem como, elementos da estrutura. Após a leitura, a professora (P2) solicitou o registro de trechos do texto que correspondessem aos seguintes questionamentos: “Quando? Onde? O que? Como?". No entanto, os alunos apresentaram dificuldade para encontrar um trecho do texto que correspondesse, especialmente, ao último item. Mesmo com a retomada da sequência narrativa pela professora e, 
com explicações individuais, os alunos ainda assim não conseguiram encontrar sozinhos informações suficientes para responder todas as questões. Esta situação sugere uma fragilidade dos estudantes quanto ao domínio da estrutura narrativa, o que compromete tanto a compreensão quanto a produção deste gênero de textos.

Em outra ocasião, percebeu-se que a professora (P2) demonstrou, novamente, preocupação em organizar previamente os tópicos a serem contemplados no texto. A partir da participação oral dos alunos, definiu os elementos (personagens, onde, quando) que deveriam ser empregados no conto de mistério a ser produzido coletivamente. Entretanto, durante a elaboração coletiva da história, os alunos não conseguiram desenvolver todos os elementos constitutivos de uma narrativa, em especial demonstraram fragilidades no desfecho. Por esse motivo, as professoras (P2 e P3) decidiram construir o último parágrafo sem a participação dos estudantes. Este fato demostra que a estratégia pedagógica empregada no ensino de como planejar a escrita de um texto não possibilitou que os estudantes realizassem/completassem a produção de forma que as professoras considerassem adequada. Abaixo o texto produzido coletivamente com a mediação das professoras e o desfecho escrito por elas.

\section{O mistério do sítio}

Em uma noite sem lua, três amigos conversavam na varanda de um sítio abandonado. Acenderam uma fogueira para espantar os mosquitos.

De repente, misteriosamente a fogueira se apagou. Um forte vento os assustou. Nesse instante os amigos viram um vulto e ficaram apreensivos. Marcos, o mais velho falou para Ana e Fábio ficarem calmos e foi pegar uma lanterna. Quando ele voltou, os três saíram caminhando para ver o que estava acontecendo. No caminho viram o balanço da árvore se movendo sozinho. Saíram berrando apavorados.

Conta-se que esse sítio estava abandonado por causa de coisas estranhas que aconteciam. Também dizem que nunca ninguém havia conseguido sair dele, apenas os três amigos.

Quadro 3: Produção coletiva - O mistério do sítio.

Assim como o planejamento é essencial no processo de produção, a revisão também contribui para a construção de bons textos, pois como afirma Antunes (2016, p.17) "[...] o desenvolvimento das competências em escrita poderá ser promovido, sobretudo, pela prática do texto planejado e revisado". Portanto, é uma etapa que precisa ser contemplada na prática pedagógica.

A seguir serão apresentadas as estratégias didáticas contempladas nas práticas pedagógicas das professoras para a revisão de textos em sala de aula, bem como, a análise dessas estratégias tendo como base os estudos desenvolvidos sobre a temática.

\subsection{0 ensino da revisão de textos na prática pedagógica}

A revisão de textos é uma atividade que pode ser proposta em diferentes etapas do processo de produção de textos. No entanto, nas práticas pedagógicas observadas, não foram identificados episódios em que a revisão tivesse sido contemplada na etapa de planejamento. As 
revisões se efetivaram durante a elaboração do texto e, principalmente, após a escrita da primeira versão, sendo quase que, exclusivamente, atividade efetuada pelas professoras.

Durante a escrita do texto destinado ao concurso cultural, os alunos do 40 ano foram orientados individualmente pelas professoras (P1 e P3), as quais indicavam o que os estudantes deveriam apagar e modificar na escrita, prevalecendo alterações relacionadas à ortografia. Além disso, uma das professoras (P1) demonstrou preocupar-se com as questões comportamentais que pudessem interferir na elaboração do texto, como se pode acompanhar na fala dela a um dos alunos: "Sente bonitinho e se concentre!" (P1).

Todos os alunos começaram pela escrita do título, conforme a solicitação da professora (P1). Alguns estudantes se queixaram da repetição dos títulos entre eles. Essa situação de conflito não foi aproveitada pelas professoras (P1 e P3) que poderiam ter promovido uma discussão sobre a determinação do título, aspecto que pode ser elaborado em qualquer fase do processo de produção, inclusive ao final da produção.

Ainda durante a produção desse texto, um dos alunos questionou o significado da palavra "origem". Um colega tentou lhe explicar, mas a professora pediu a ele que deixasse o amigo pensar e responder, impedindo a interação em sala de aula. Com relação à interação, verificou-se que em diferentes momentos a professora (P1) pedia aos alunos que não conversassem, embora as mesas estivessem agrupadas de duas em duas.

No 5 o ano, durante a produção coletiva do conto de mistério a professora (P2) solicitou que os alunos a auxiliassem no aperfeiçoamento de um dos trechos do texto. Aproveitando para lembrá-los da importância de reler o texto durante a textualização. Em alguns momentos, ela valorizou as alterações julgadas relevantes pelos alunos, em outros, decidiu como fazê-las, como por exemplo, ao solicitar a ajuda dos estudantes para verificarem a mudança necessária na frase: "Nesse instante os amigos viram um vulto e logo ficaram apreensivos". Mesmo com a participação ativa deles, a professora (P2) decidiu pela retirada da palavra "logo", impedindo-os de apresentarem suas hipóteses e refletirem sobre a construção final da frase "Nesse instante os amigos viram um vulto e ficaram apreensivos".

Durante a reescrita deste mesmo conto, o qual foi corrigido previamente, a professora (P2) percebeu a dificuldade dos alunos quanto ao uso das palavras "mal e mau". Escreveu-as no quadro, questionou os alunos quanto às diferenças entre elas e, também, citou a palavra "malassombrada" que estava presente em alguns textos anteriormente trabalhados em sala de aula. Neste momento, vários alunos tentaram se manifestar tentando ampliar a discussão, porém, a professora (P2) prosseguiu com a explicação orientando-os a utilizarem a estratégia de troca da palavra "mal" pelo antônimo (bem e bom), de modo a garantir a escrita correta. Posteriormente, a professora (P2) percebeu outra dúvida dos alunos em relação ao uso de "mais" e "mas" e comentou com o grupo "Tem mais um probleminha que está se repetindo". Em seguida, registrou as palavras no quadro e perguntou aos alunos em que situação utilizaria cada uma delas, finalizando com a explicitação de quando e como utilizá-las. Um aluno lembrou-se de outras 
palavras que também poderiam causar confusão (sob e sobre), e o próprio aluno explicou os significados desses termos.

A retomada de conteúdos durante a revisão é uma estratégia didática recomendada por Antunes (2016) e Brandão (2007). Para aprimorar essa prática, a professora (P2) poderia ter explorado os exemplos retirados dos textos dos próprios alunos, como fez com as palavras "mau e mal" e "mais e mas". Também, poderia ter ampliado o tempo disponível para a reflexão sobre o uso deste novo vocabulário, de modo que os estudantes expusessem suas hipóteses e houvesse maior discussão sobre as palavras, seus significados e usos, para então prosseguir com a explicação.

Em dois outros episódios, ainda no 50 ano, os alunos revisaram coletivamente textos narrativos reescritos individualmente. No primeiro, ocorreu a revisão de uma lenda que objetivava a (re)organização dos parágrafos, bem como, a pontuação do texto. No segundo episódio, foi efetuada a reescrita de um romance com a modificação do narrador da história.

Após a reescrita da lenda, a professora (P2) solicitou que alguns alunos fizessem a leitura para o grupo, enquanto ela registrava o texto no quadro. Neste momento, um aluno demonstrou dúvidas quanto aos sinais de pontuação. Por isso, a professora (P2) retomou este conteúdo, perguntando aos alunos o significado dos sinais: reticências, dois-pontos e travessão, e registrou as respostas no quadro, sem acrescentar qualquer informação ao que foi dito pelos alunos. Destaca-se que quando um dos alunos explicou a função das reticências, a professora (P2) comentou: "Ainda bem que tem o L. Imagina senão tivesse ele na sala?".

Nesse episódio foi possível verificar que a professora (P2) retomou um conteúdo importante, que os alunos devem dominar neste ano escolar. No entanto, o ensino poderia ter sido mais efetivo, ou seja, seria conveniente que ela ampliasse o conhecimento dos alunos no que diz respeito aos sinais que foram fonte de dúvidas. Além disso, ao fazer um comentário inadequado quando se referiu à resposta do aluno L., ela provavelmente desencorajou a participação dos outros estudantes na revisão coletiva.

Ainda nesse episódio, houve a discussão do grupo sobre o uso de vírgula, a partir do comentário da professora (P2) de que algo não estava combinando numa das frases. Os alunos concordaram e, alguns, sugeriram trocar o lugar da vírgula na frase "O soberano conhecido, por sua generosidade, perguntou-lhe o seguinte...", dizendo, por exemplo: "Bota na frente de 'soberano' e, depois de 'generosidade'". No entanto, as vírgulas já estavam empregadas corretamente no texto original, sendo necessário apenas discutir a razão de serem utilizadas em determinados trechos. Essa discussão não ocorreu, assim perdeu-se a oportunidade de promover a reflexão sobre elementos que conferiam tanto a coesão, como também, coerência do texto.

Em síntese, no que se refere à pontuação a professora não realizou um ensino explícito tentando distinguir os sinais pausais (vírgula, ponto, e ponto e vírgula) dos sinais melódicos, que marcam a entoação (reticências, dois-pontos e travessão.) (Cunha \& Cintra, 2008, p. 656). 
Gombert (1992) definiu o monitoramento da coerência, da coesão, além da reflexão sobre a estrutura textual, como propriedades do desenvolvimento metatextual. Por essa razão, Spinillo (2009) denominou a revisão como atividade metatextual, uma vez que possibilita aos estudantes refletir e empregar de forma intencional diferentes elementos linguísticos, sendo, portanto, uma atividade fundamental à produção de bons textos.

No episódio em que os alunos reescreveram um romance modificando o narrador, havia necessidade de dar coerência à escrita efetuando diversas mudanças no texto. No entanto, houve pouca exploração desse elemento linguístico pela professora (P2) que afirmou "A mudança não fará tanta diferença" (P2) quando um dos alunos corrigiu seu colega ao dizer-lhe que ao invés de escrever "O jovem morreu num bombardeio", deveria registrar "O meu dono morreu num bombardeio!".

Além disso, a professora (P2) poderia ter explicado que ao escrever uma narrativa o escritor pode assumir a posição de narrador-observador ou de narrador-personagem. Assim, o narrador-personagem escreve sobre ele mesmo, empregando a primeira pessoa. De outra parte, o narrador-observador não participa dos fatos, e conta o que aconteceu às personagens, portanto deve empregar a terceira pessoa.

No diálogo a seguir é possível verificar, novamente, que as discussões em sala de aula poderiam ter sido potencializadas, especialmente, quando relacionadas à coerência textual. Tais discussões poderiam beneficiar a aprendizagem dos estudantes.

P2: "Aqui ela acrescentou algumas palavras que não mudaram o sentido".

A3: "Isso que eu ia perguntar, se eu posso colocar algumas palavras".

A2: "É porque não pode mudar o contexto da história. Fui na Biblioteca Pública do Paraná e a contadora de histórias contou de outro jeito. Eu percebi porque emprestei o livro e estava diferente".

P2: "É como fofoca, cada um escreve ou conta à sua maneira. No texto não é possivel mudar, apenas acrescentar coisas para dar a concordância".

Verifica-se que a professora (P2) poderia ter explicado as situações levantadas pelos estudantes, uma vez que envolviam aspectos da coerência textual, um dos primeiros elementos linguísticos a serem explorados durante a revisão, segundo Brandão (2007). Além disso, a professora (P2) poderia ter envolvido os alunos na atividade de revisar o texto, valorizando as situações expostas por eles ao promover a reflexão sobre o que havia sido registrado por um dos colegas.

Para Castedo e Ferreiro (2013) "durante as situações de revisão coletiva procura-se explicitar os problemas decorrentes da interpretação do escrito por parte das crianças que não são autoras do mesmo. Deste modo, os autores são levados a interagir com leitores potenciais" (p.391).

Essa estratégia didática de revisar coletivamente um texto é, portanto,

[...] o momento de maior intervenção docente, tanto para apontar problemas não percebidos pelas crianças como para sistematizar algumas soluções que já foram 
compreendidas por todos. É, assim mesmo, o momento privilegiado em que o adulto age como 'modelo' de escritor que revisa um escrito, colocando à disposição das crianças uma série de atitudes e estratégias que não são observáveis a partir do produto escrito (Castedo \& Ferreiro, 2013, p. 392).

De modo semelhante, pode-se propor a revisão em equipes. Nesse caso, os alunos se reúnem para analisar os textos produzidos pelos integrantes do grupo. A intervenção da professora se torna indireta para garantir que os próprios alunos atuem enquanto revisores. A orientação docente se limita a indicar as possibilidades de alterações, as quais poderiam passar despercebidas pelos alunos, bem como, lembra-os dos conhecimentos linguísticos adquiridos em outras situações de aprendizagem, que podem ser empregados na ocasião (Castedo \& Ferreiro, 2013 , p. 393). Salienta-se que a revisão realizada com a colaboração de um ou mais colegas possibilita alterações mais significativas do que quando efetuada individualmente. Essa constatação foi apresentada por diferentes pesquisadores brasileiros (Andrade, 2010; Dutra, 2012; Spinillo, 2015), que argumentam sobre a importância de revisar o texto em pares.

Além de potencializar as alterações na produção, a revisão colaborativa contribui para a compreensão do texto, uma vez que os revisores terão necessidade de ler o material escrito para refletir sobre os elementos linguísticos que o constituem. Nessa perspectiva, Pereira (2008) argumenta que a leitura e a escrita se apresentam interligadas na revisão de textos. No entanto, embora importante para a competência dos estudantes na escrita, a revisão colaborativa não foi proposta pelas professoras das turmas observadas.

No 4ํano, dois episódios retratam situações de revisões efetuadas após a correção dos textos (informativo e narrativo) pelas professoras (P1 e P3).

É importante destacar que durante a escrita do texto informativo sobre o pão, os alunos realizaram algumas revisões, a partir de sugestões das professoras. Entretanto, a maior parte da revisão dos textos se deu somente após a correção feita pela professora (P1) da primeira versão dos textos. Para corrigir os textos dos alunos, a professora (P1) solicitou que eles se dirigissem à sua mesa para que ela pudesse indicar o que precisariam alterar como é possível acompanhar na fala dela a alguns dos alunos: "Hoje é com ' $H$ ' maiúsculo. Aqui é 'J' e não ' $G$ '.". "R. cadê os parágrafos? Nenhum espacinho de parágrafo! Coloca mais prá cá então". Ainda, após pedir à aluna para ler um trecho do texto que escreveu, comentou: "Você falou 'passava'. Leia o que você escreveu...". A aluna fez a leitura ("Você passa...") e percebeu que o mesmo estava inadequado.

Observa-se que a professora ( $P 1$ ) se deteve em corrigir palavras escritas equivocadamente nos textos e, não, em promover a reflexão sobre a língua, especialmente no que se refere à flexão do verbo. Dalla-Bona (2012) denominou a revisão no final da primeira versão do texto de reescrita, afirmando que essa atividade influencia positivamente a competência do estudante na produção quando "[...] não se limita a uma atividade de mera correção de itens indicados pelo professor no texto dos alunos" (p.289). Por essa razão, recomenda que a escola desenvolva atividades de escrita em que o(s) autor (es) percebam que a elaboração de mais de uma versão para o texto é um procedimento essencial aos escritores. 
Em outro episódio, após a elaboração da primeira versão de um desfecho para o conto João e Maria, ocorreu a revisão individual com a intervenção da professora (P3). Todos os alunos elaboraram o final para a história, no entanto, apenas dois textos foram selecionados para a revisão individual, pois segundo a explicação da professora (P3) correspondiam aos estudantes que apresentavam dificuldades acentuadas relacionadas à paragrafação, à ortografia e à gramática na escrita de textos.

A estratégia adotada pela professora (P3), durante a revisão, foi questionar os alunos quanto aos equívocos apresentados nas produções, sendo que a ortografia foi um dos elementos linguísticos que precisou ser retomado, uma vez que se mostrou como uma grande dificuldade dos dois estudantes.

Embora eles tenham sido orientados quanto à ortografia, verificou-se que nem todas as palavras foram corrigidas e outras que estavam corretas foram grafadas de forma incorreta pelo estudante, como é possível visualizar no quadro 4.

\begin{tabular}{|c|c|c|}
\hline \multicolumn{1}{|c|}{ 1a VERSÃO } & 2a VERSÃO \\
\hline DE REPENTE UMA SENHORA MUITO MAL VA DA OLHOU & DEREPENTE UMA SENHORA MUITO MALVADA OLHOL PELA PORTA E FICOL \\
PELA PORTA E FIGOU OLHANDO JOÃO E MARIA & OLHNDO PELA PORTA E FICOU OLHANDO JOÃO E MARIA COMENDO \\
COMENDOSUA CASA DE DOCES EN TÃO E LA SAIU DE SUA & SUACASADEDOCES. \\
CASINHA E ELA VIL OS DOIS SATISFEIDOS E DORMIRÃO & ENTÃO ELA SAIU DE SUA CASINHA E VIU OS DOIS SATISFEITOS E DORMINDO. \\
ENTÃO A BRUXA LEVOL ELES PARA DENTRO DE SUA CASA E & A MALEVULA LEVOU ELES PARA DENTRO DE SUACASA E COLOCOUA MARIA \\
GOLOCOL A MA RIA EM UMA GAIOLA E O JOÃO IN PREGA & DENTRO DE UMA GAIOLA E O JOÃO DE EMPREGADO. \\
DO E UM DIA ELA DISE MENINO LIQUE O GALDEIRÃO VOL & UM DIA A BRUXA DISE.. \\
COMER ELA OGE ENTÃO E LE PEGUNTOL COMO LIGA O & - MENINO LIGUE O CALDEIRÃO PORQUE VOU COMER AMARIA HOJE. \\
CAL DEIRÃO ENTÃO ELA LIGOL E O JO ÃO ENPUROL A & ENTÃO O JOÃO PERGUNTOL.. \\
BRUXA NO GAL DEIRÃO E A BRUXA PUXOL O JOÃO JUNTO & - COMO LIGA O GALDEIRÃO? \\
E A MARI A CONSEGUIU SAIR DA JALA JUNTO E A MARI A & A BRUXA LIGOU O GALDEIRÃO E O JOÃO EMPUROU A BRUXA NO CALDEIRÃO E A \\
CONSEGUIU SAIR DA JALA E GONSEQUIU SAL VAR O JOÃO & BRUXA EMPUROU O JOÃO JUNTO. MAS A MARIA CONSEGUIU AS IR DA GAIOLA E \\
E A BRUXA MOREL. & SALVAR O JOÃO E A BRUXA MORREU. \\
& A11 & \\
\hline
\end{tabular}

Quadro 4: Final diferente para conto João e Maria.

Destaca-se que no texto do aluno N. havia várias dificuldades relativas à segmentação lexical convencional. Assim, no quadro 4 é possível observar doze hipersegmentações na 1a versão do texto e uma na $2^{a}$ versão. Quanto às hipossegmentações identifica-se uma na 1 à versão e quatro na segunda versão.

Entretanto, estas dificuldades dos alunos não foram adequadamente trabalhadas pela professora. Conforme explica Guimarães (2013), tanto na aquisição inicial como nos sujeitos com dificuldades na escrita a noção de palavra está baseada em unidades de significação. Por isso, as crianças reconhecem com mais facilidade as palavras que representam ideias, ou seja, as palavras lexicais ou de conteúdo, mas apresentam dificuldades na escrita de palavras que não possuem significados que possam ser tomados como uma unidade de significação independente do universo linguístico - como é o caso das preposições, artigos e conjunções, ou seja, nas palavras de forma ou palavras gramaticais. Portanto, quando os alunos apresentam problemas de hiper e hipossegmentação o trabalho pedagógico deve focalizar este tipo de explicação, para que as 
crianças possam desenvolver maior capacidade na segmentação lexical convencional.

Nesse episódio, a professora (P3) orientou o estudante quanto à estrutura da narrativa, como por exemplo, organização do texto em parágrafos e uso de travessão nas falas dos personagens. Outra orientação ocorreu em relação a não repetição da palavra "bruxa", o que segundo a professora afetaria a coesão textual.

Embora as orientações concedidas sejam relevantes para o aprimoramento da escrita, poderia ter focalizado um menor número de itens, para garantir que o aluno os apreendesse. Talvez, uma das questões mais importantes fosse enfatizar a coerência textual, como sugere Brandão (2007).

Destaca-se que neste episódio os textos foram analisados individualmente. No entanto, acredita-se que se os alunos tivessem realizado a análise dos seus textos em parceria poderiam beneficiar-se um do conhecimento do outro, como por exemplo, o que ocorreu em um único momento de interação quando um dos alunos explicou ao colega que ele deveria utilizar a palavra "mas", ao invés de "mais", por estar relacionada a uma ideia contrária.

Ainda, durante o episódio, foi possível perceber que a revisão individual se constitui num desafio para os professores. Como comentou a professora (P3), embora tenhamos revisado e aprimorado apenas dois textos, outros vinte e cinco precisariam ser revisados. Por isso, enfatizase que a revisão coletiva é uma estratégia pedagógica importante, pois os alunos não precisam refletir especificamente sobre os elementos linguísticos utilizados em suas próprias produções, eles podem aprender muito analisando e compreendendo os erros e acertos nas produções dos colegas.

Diante disso, acredita-se na importância de incluir nas práticas escolares e na aula de língua principalmente diferentes estratégias didáticas, como as que foram citadas ao longo desse artigo, de modo a possibilitar que todos os escritores tenham a oportunidade de efetivarem a revisão de suas composições. Além disso, é igualmente necessário que se promova no contexto escolar a interação entre os alunos, de modo que no processo de produção os estudantes possam ter oportunidades de revisarem textos em duplas ou em trios, o que poderá promover um intercâmbio de conhecimentos e maior aprendizagem para todos.

\section{CONCLUSÃO}

Existe expressivo suporte teórico para a afirmação de que as ações de planejar e revisar os textos escritos favorecem seu aperfeiçoamento, pois são atividades que possibilitam o aprimoramento da escrita (estrutura textual, coesão e coerência) que dá suporte à transmissão do conteúdo (uso comunicativo do texto). Assim, as ações de planejar e revisar a própria produção textual possibilitam aos estudantes o aumento do domínio da capacidade de escrita.

Nessa perspectiva, este estudo teve como objetivo analisar o trabalho pedagógico de professoras de 4으 e 5o anos, no que se refere ao processo de ensino-aprendizagem do 
planejamento e da revisão de textos em sala de aula. Além disso, buscou identificar se as estratégias pedagógicas adotadas pelas professoras contribuíram para a melhora no desempenho em escrita dos alunos.

No que se refere ao planejamento, verificou-se na prática pedagógica das professoras participantes do estudo dois tipos de estratégias: no período que antecedia a produção, eram lidos diferentes textos, como exemplo do gênero que deveria ser produzido; era explicitada a organização tópica dos textos que deveriam ser escritos (produzidos). Em relação às atividades de ensino da revisão de textos observou-se que as docentes priorizaram correções relacionadas à ortografia e gramática, corroborando a constatação de Antunes (2016) de que esse tipo de correção tem prevalecido nos encaminhamentos docentes. Além disso, as revisões eram efetivadas sempre depois que uma primeira versão do texto estava terminada e realizadas quase que exclusivamente pelo professor e não pelos alunos - como parte integrante do processo de ensino-aprendizagem.

Dessa forma, conclui-se que os encaminhamentos pedagógicos observados não possibilitaram aos estudantes relevante melhoria na capacidade de produção textual, conforme pode-se verificar pelos problemas de coesão e coerência, bem como pela ausência dos elementos prototípicos dos diferentes gêneros textuais nas produções dos alunos.

Os resultados deste estudo têm importantes implicações educacionais, pois sugerem que a prática pedagógica para o desenvolvimento da capacidade de produção textual pode ser aprimorada. Na realidade, o ensino explícito de como realizar o planejamento da escrita de um texto pode contribuir para uma maior capacidade de escrita nos alunos. Esse ensino deve auxiliar os alunos a empregar estratégias como: realizar um rol dos conteúdos a serem abordados no texto (delimitação adequada do conteúdo), balizar a escrita do texto de acordo com a estrutura textual do gênero que que será produzido, além de realizar uma definição prévia dos objetivos, do destinatário e da finalidade do texto que será escrito. De outra parte, salienta-se a necessidade de incutir nos alunos a noção de que produzir um texto é uma atividade recursiva, ou seja, a revisão permanente do escrito é que permite o seu aperfeiçoamento. 


\section{REFERÊNCIAS}

Abaurre, M. B. M., Fiad, R.S., Mayrink-Sabinson, M.L.T. (1997). Cenas de aquisição da escrita: o sujeito e o trabalho com o texto. Campinas: Mercado das Letras.

Andrade, R.M.B.L. (2010). Revisão de cartas de reclamação: reflexões sobre as modificações realizadas por crianças. Dissertação de Mestrado. Universidade Federal de Pernambuco. Recife, PE.

Antunes, I. (2016). Práticas pedagógicas para o desenvolvimento das competências em escrita. Em F. A. Coelho \& R. Palomanes (Orgs.). Ensino de produção textual (pp. 9-21) São Paulo: Contexto.

Calkins, L.M. (2002). A arte de ensinar a escrever: o desenvolvimento do discurso escrito. (D. Batista, Trad.) Porto Alegre: Artmed. (Trabalho original publicado em 1986)

Castedo, M. \& Ferreiro, E. (2013). Produção e revisão de epígrafes em situação didática com crianças de 7 e 9 anos. EM E. Ferreiro. $O$ ingresso na escrita e nas culturas do escrito: seleção de textos de pesquisa. (pp. 385-419). São Paulo: Cortez, 2013.

Costa, M.C.F. (2010) O papel da revisão textual em textos reescritos por crianças. Dissertação de Mestrado. Universidade Federal de Pernambuco, Recife, PE

Cunha, C. \& Cintra, L.F.L. (2008). Nova gramática do português contemporâneo (5a ed.). Rio de Janeiro: Lexikon.

Dalla-Bona, E.M. (2012). Letramento literário: ler e escrever literatura nas séries iniciais do ensino fundamental. Tese de Doutorado. Universidade Federal do Paraná. Curitiba, PR.

D’Elia, M.E.R. (2007). O texto do professor no texto do aluno: intenções e significado. Dissertação de Mestrado. Universidade Estadual de Campinas. Campinas, SP.

Dutra, E.F. (2011). A revisão textual nos anos iniciais da escolaridade: percursos e procedimentos. Dissertação de Mestrado. Universidade de São Paulo. São Paulo, SP.

Gombert, J.E. (1992). Metalinguistic Development. Hertfordshire: Harvester Wheatsheaf.

Guimarães, S.R.K. (2013) The role of morphosyntactic awareness in conventional lexical segmentation. Paidéia, 23 (55), 225-233.

Hayes, J.R. \& Flower, L. (1980). Identifying the organization of writing processes. Em L.W. Gregg \& E. R. Steinberg (Orgs.). Cognitive processes in writing: an interdisciplinary approach. (pp. 3-30) Hillsdale, NJ: Lawrence Erlbaum.

Jolibert, J. (1994). Formando crianças produtoras de texto. Porto Alegre: Artmed.

Koch, I.V. \& Elias, V.M. (2016). Escrever e argumentar. São Paulo: Contexto.

Leal, T.F. \& Melo, K.L.R. de. (2007). Produção de textos: introdução ao tema. Em T. F. Leal \& A. C. P. Brandão (Orgs.). Produção de textos na escola: reflexões e práticas no ensino fundamental (pp. 11-27) Belo Horizonte: Autêntica. 
Lucena, R.N. (2013). A revisão no planejamento, na textualização e na edição: estudo sobre as habilidades das crianças de planejar, revisar e refletir sobre as alterações no texto. Tese de Doutorado. Universidade Federal de Pernambuco. Recife, PE.

Melo, K.L.R. \& Silva, A. da (2007). Planejando o ensino de produção de textos escritos na escola. Em Em T. F. Leal \& A. C. P. Brandão (Orgs.). Produção de textos na escola: reflexões e práticas no ensino fundamental (pp. 81-98). Belo Horizonte: Autêntica.

Nascimento, C.E.R. (2009). Escrevendo relatórios em sala de aula: gênero discursivo, circulação e referenciação. Dissertação de Mestrado. Universidade Estadual de Campinas. Campinas, SP.

Pereira, L.A. (2008). Escrever com as crianças: como fazer bons leitores e escritores. Porto: Porto Editora.

Rocha, G. (1999). A apropriação das habilidades textuais pela criança. Campinas: Papirus.

Spinillo, A.G. (2009). A consciência metatextual. Em M. da Mota (Org.). Desenvolvimento metalinguístico: questões contemporâneas (pp. 77-113). São Paulo: Casa do Psicólogo.

Sampieri, R. H., Collado, C. F. \& Lucio, M. del P. (2013). Metodologia de Pesquisa (5a ed.). Porto Alegre: Penso.

Spinillo, A.G. (2015). "Por que você alterou isso aqui?" As razões que as crianças adotam quando fazem alterações ao revisar seus textos. Letras de Hoje, 59(1), 32-39.

Travaglia, L.C. (2016). Planejamento de textos para sua produção. EM F. A. Coelho \& R. Palomanes (Orgs.). Ensino de produção textual (pp. 87-107). São Paulo: Contexto. 